\title{
Olivopontocerebellar atrophy of neonatal onset and disialotransferrin developmental deficiency syndrome
}

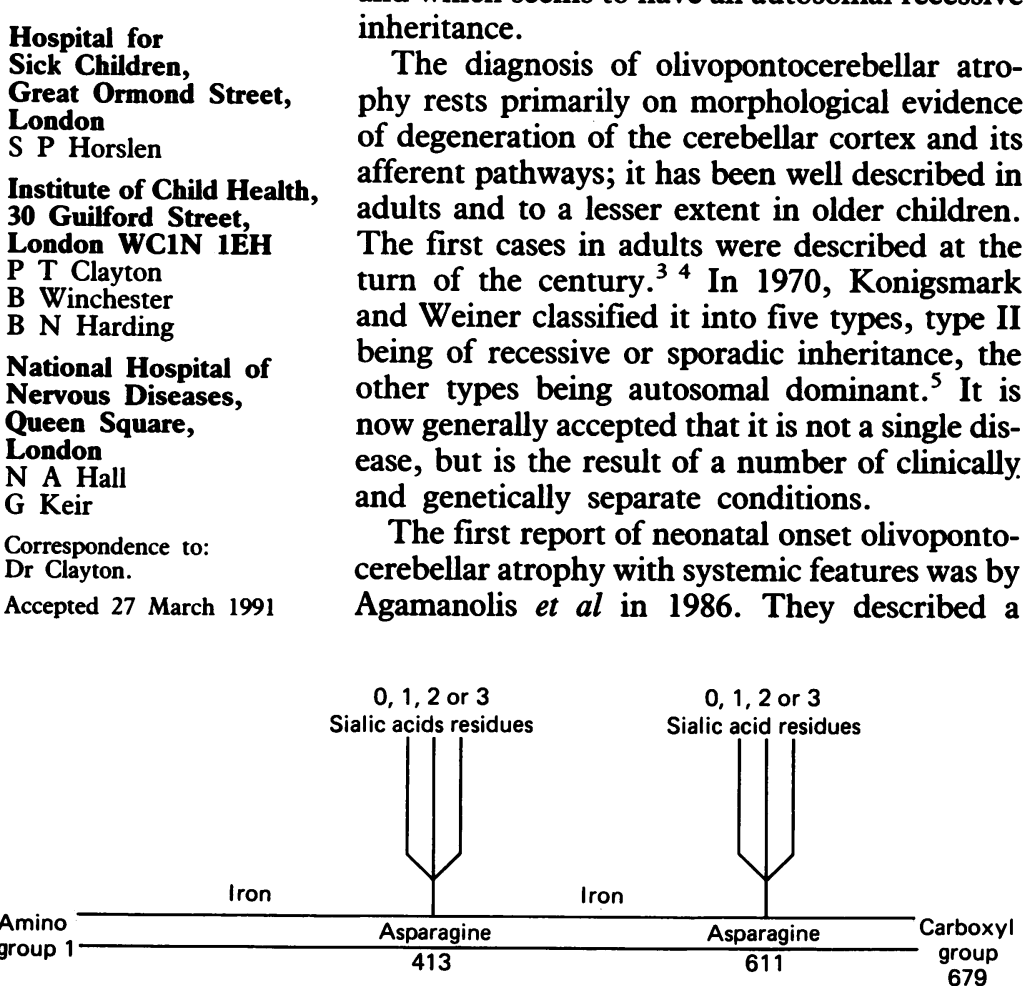

Figure 1 Diagram of human transferrin molecule showing positions of the glycan chains, each of which may have 0-3 sialic acid residues attached. The protein is divided into two domains, $N$ t and $C t$, each of which can bind one ferric ion. brother and sister with the condition and suggested that it may have been caused by a primary lipoprotein disorder. ${ }^{1}$ Harding et al, two years later, noticed low serum concentrations of thyroid binding globulin and caeruloplasmin in the two cases that they reported, thus raising the possibility of an abnormality of glycoproteins, although this was not formally stated in their paper. ${ }^{2}$

A less severe disorder has been described in recent years with many features in common with olivopontocerebellar atrophy of neonatal onset including failure to thrive, developmental delay, hypotonia, retinal abnormalities, liver disease, joint restrictions, pericardial effusions, and cerebellar hypoplasia or atrophy. This has been named disialotransferrin developmental deficiency (DDD) syndrome ${ }^{6}$ or carbohydrate deficient glycoprotein syndrome. ${ }^{7}$

Abnormalities of glycoproteins have been found in patients with DDD syndrome, ${ }^{6-10}$ the most specific biochemical marker being an alteration in the glycosylation pattern of serum transferrin. $^{6}{ }^{10}$ Transferrin is one of the main serum glycoproteins that transport iron, and it has two $\mathbf{N}$ linked glycosylation sites (fig 1). Separation of transferrins in clinical samples by isoelectric focusing may resolve up to seven transferrin bands containing between 0 and 6 sialic acid residues. ${ }^{11}$ In normal serum, transferrin with four sialic acid residues (tetrasialotransferrin) predominates, but in serum from patients with DDD syndrome there is a pronounced reduction in tetrasialotransferrin and a corresponding increase in components containing 0 and 2 sialic acid residues (asialotransferrin and disialotransferrin). ${ }^{6} 10$

In view of the clear clinical similarities between neonatal onset olivopontocerebellar atrophy and DDD syndrome it is important to look for abnormalities in serum glycoproteins in cases of olivopontocerebellar atrophy of neonatal onset. ${ }^{12}$ We report two further cases in which plasma transferrin that is deficient in sialic acid has been specifically sought.

Case reports, subjects, and methods CASE REPORTS

Case 1

This boy was the third child of unrelated white parents who already had two daughters who were entirely well. He was born at 37 weeks' gestation, after presenting in a double footling position. The pregnancy had been uneventful. He weighed $2800 \mathrm{~g}$ at birth, and Apgar scores were 3 at 1 minute and 10 at 5 minutes. Because of some floppiness and grunting the infant was 
admitted to the special care baby unit but settled rapidly and was soon established on full breast feeding. It was noted, however, that he had a relatively large head circumference (38 $\mathrm{cm},>90$ th centile), puffy feet, and limited abduction of the hips. His chromosomes were therefore checked and found to be normal male (46XY). Despite feeding well at home he failed to thrive and at the age of 6 weeks some facial oedema was noticed. He smiled at 7-8 weeks but showed little sign of visual fixation, and no head control. At 3 months of age he was admitted to his local hospital with increasing oedema and abdominal swelling and was transferred to the Hospital for Sick Children for further investigation.

On examination he had a large head with a prominent occiput, a high forehead, an antimongoloid slant to his eyes, low set ears, and a

Table 1 Liver function tests at the time of admission to the Hospital for Sick Children

\begin{tabular}{lcrl}
\hline & $\begin{array}{c}\text { Case } \\
\text { No 1 }\end{array}$ & $\begin{array}{l}\text { Case } \\
\text { No 2 2 }\end{array}$ & $\begin{array}{l}\text { Reference } \\
\text { range }\end{array}$ \\
\hline Total bilirubin ( $\mu \mathrm{mol} / \mathrm{l})$ & 14 & $<12$ & $<17$ \\
Total protein $(\mathrm{g} / \mathrm{l})$ & 29 & 45 & $61-78$ \\
Albumin $(\mathrm{g} / \mathrm{l})$ & 20 & 24 & $35-55$ \\
Alanine aminotransferase (U/l) & 101 & 64 & $10-35$ \\
Aspartate aminotransferase (U/l) & 164 & 118 & $20-50$ \\
\hline
\end{tabular}

small mandible. He had a wasted appearance with a distended abdomen, gross ascites, bilateral inguinal hernias, and moderate enlargement of the liver. His spleen was not palpable. His cardiovascular and respiratory systems seemed to be normal. He had complete visual inattention and roving eye movements, severe head lag, and truncal hypotonia. On ophthalmological examination there was optic disc pallor but no other ocular abnormality. He had restricted extension of the knees, abduction of the hips, and dorsiflexion of the ankles.

An abdominal ultrasound scan confirmed the presence of ascites and hepatomegaly. Chest radiographs, skeletal survey, and cranial ultrasound scans showed no abnormalities, but cranial computed tomograms showed dilated ventricles and subarachnoid spaces. An echocardiogram showed no pericardial effusion but suggestd some thickening of the walls of both ventricles. The electroencephalogram and electromyogram showed no abnormalities but results of the electroretinogram and visual evoked response were abnormal suggesting some alteration of function in the posterior part of the left hemisphere. The brainstem auditory evoked response suggested a significant loss of peripheral auditory function. Standard biochemical investigations showed that the serum

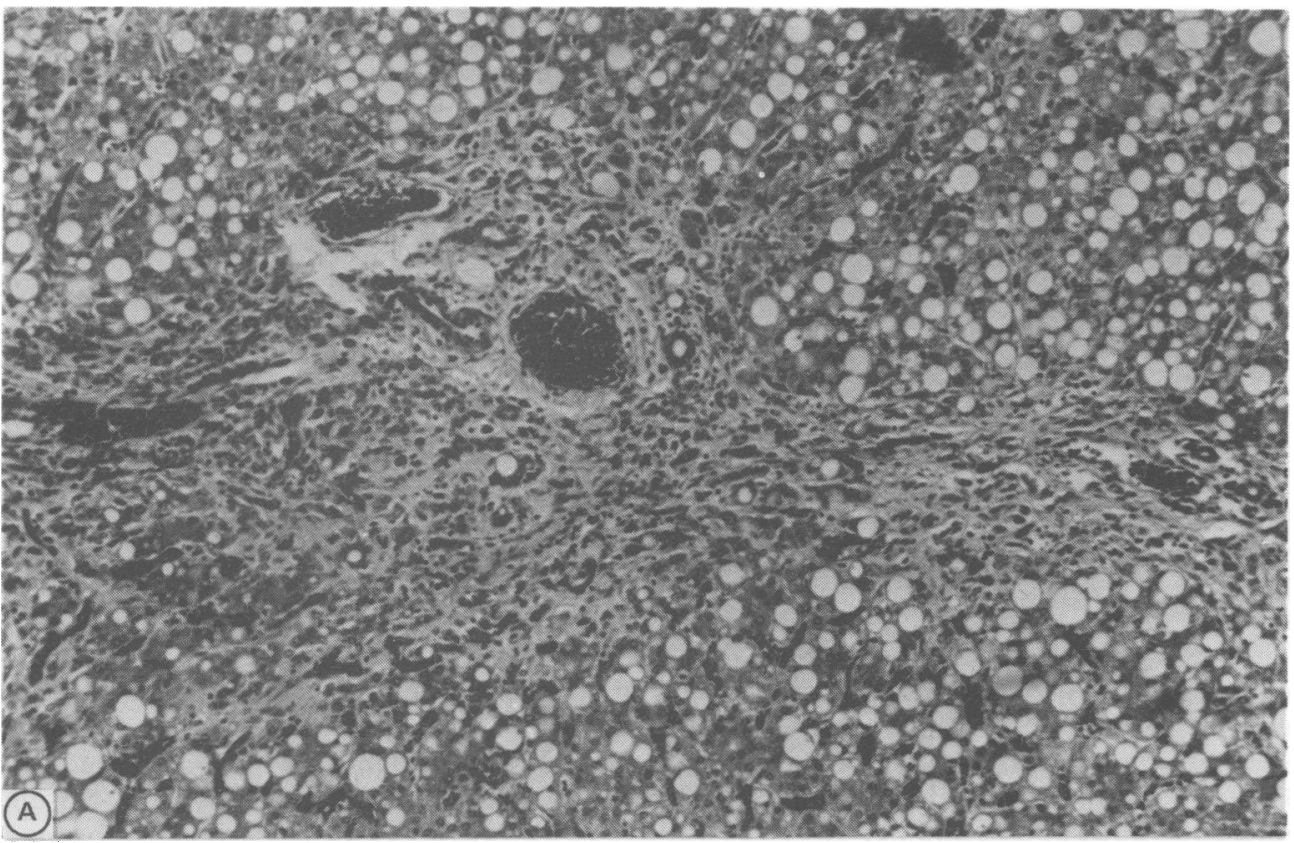

Figure 2 (A) Case 1: histological section of liver showing fatty infiltration and abnormal bile duct plates (haematoxylin and eosin stain $\times 75$ ). (B) Immunoperoxidase staining for cell adhesion molecule $5 \cdot 2$ shows that abnormal bile ducts extend from the portal tracts, magnification $\times 30$. (C) Case 1 : histological section of the kidney showing tubular cystic dilatation (haematoxylin and eosin stain $\times 30$ ).
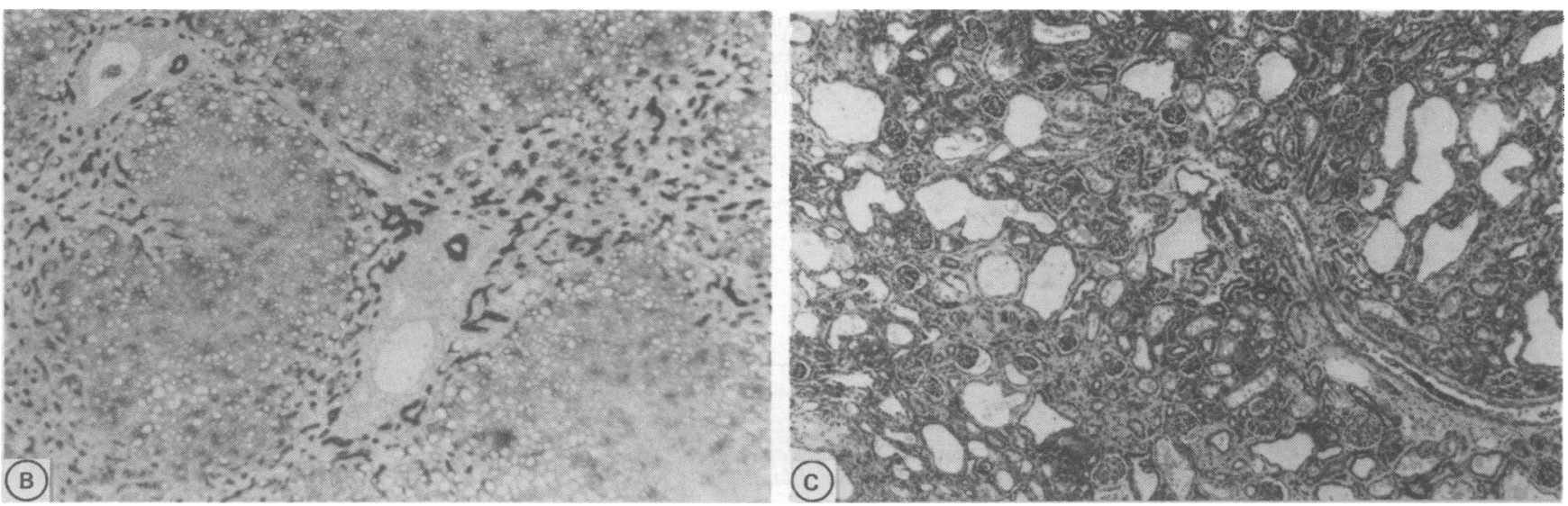
albumin and total protein concentrations were abnormally low, and transaminase activities were high, indicating hepatic disease (table 1). The plasma electrolyte, urea, and creatinine concentrations were within the reference range. Of the amino acid concentrations in plasma, taurine and glycine were raised. Urinary screen for organic acids, amino acids, glycosaminoglycans and reducing substances showed no abnormality. $\alpha_{1}$-Antitrypsin concentration was just below the lower limit of the reference range at $19 \cdot 2 \mu \mathrm{mol} / 1$ (20-40 $\mu \mathrm{mol} / \mathrm{l})$.

After treatment with diuretics and albumin his condition improved. He became oedematous again during an episode of diarrhoea, however, and required further albumin. Transfer back to the referring hospital was being arranged when he suddenly became restless with an irregular breathing pattern and died soon afterwards. He was 15 weeks old at the time of death.

Necropsy confirmed the finding of thickened ventricular walls, although no other cardiac abnormalities were discovered. The liver was enlarged and fatty and histological examination showed macrovesicular fatty change, ductal plate abnormalities, and portal fibrosis (fig 2). The kidneys were enlarged and pale; microscopically there was pronounced cystic dilatation of the tubules and collecting ducts, but the glomeruli were unaffected. The fixed brain weighed $560 \mathrm{~g}$ (normal for age), but the hindbrain accounted for only $18 \mathrm{~g}, 3 \%$ of the total (normal is $11 \%$ of total), the cerebellum being small with narrow prominent folia while the base of the pons was flattened (fig 3). Histological examination of the cerebellum showed sub- total loss of Purkinje cells and granule cells, and extensive depletion of the white matter accompanied by widespread gliosis, but the dentate nuclei and their outflow through the superior cerebellar peduncles were well preserved. Neuronal loss from pontine nuclei and inferior olives was severe, and the middle and inferior cerebellar peduncles and the transverse pontine fibres were extremely atrophic. Several sections of the spinal cord were normal.

\section{Case 2}

This boy was the brother of case 1 and was born just over two years later. He was delivered at term after an uneventful pregnancy. The Apgar scores were good and he weighed $2900 \mathrm{~g}$ at birth. In view of the previous child's history, the first examination was carried out by a consultant paediatrician, who thought he was normal. The baby fed well immediately and was discharged home 24 hours after birth.

At 4 weeks of age, however, he was referred to the Hospital for Sick Children by his general practitioner because of failure to thrive, vomiting, and abnormal eye movements. He had failed to gain any weight since birth and was now below the 3rd centile for his age. He was thin and wasted and had a prominent occiput and low set ears like his brother. Cardiovascular and respiratory systems seemed normal. His liver was palpable $1.5 \mathrm{~cm}$ below the costal margin and was soft and smooth. There was no ascites and no abdominal distention. Neurological examination showed general hypotonia with poor head control, roving eye movements, and

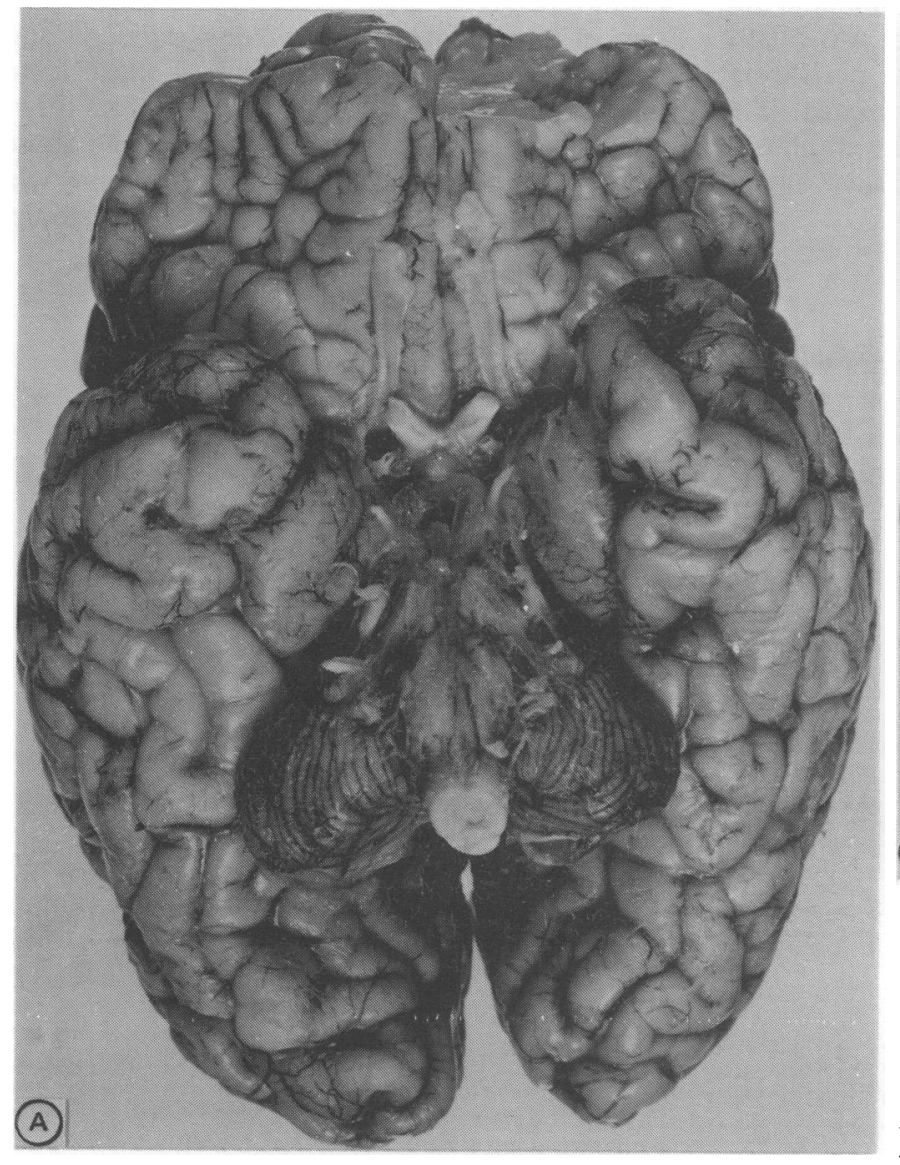

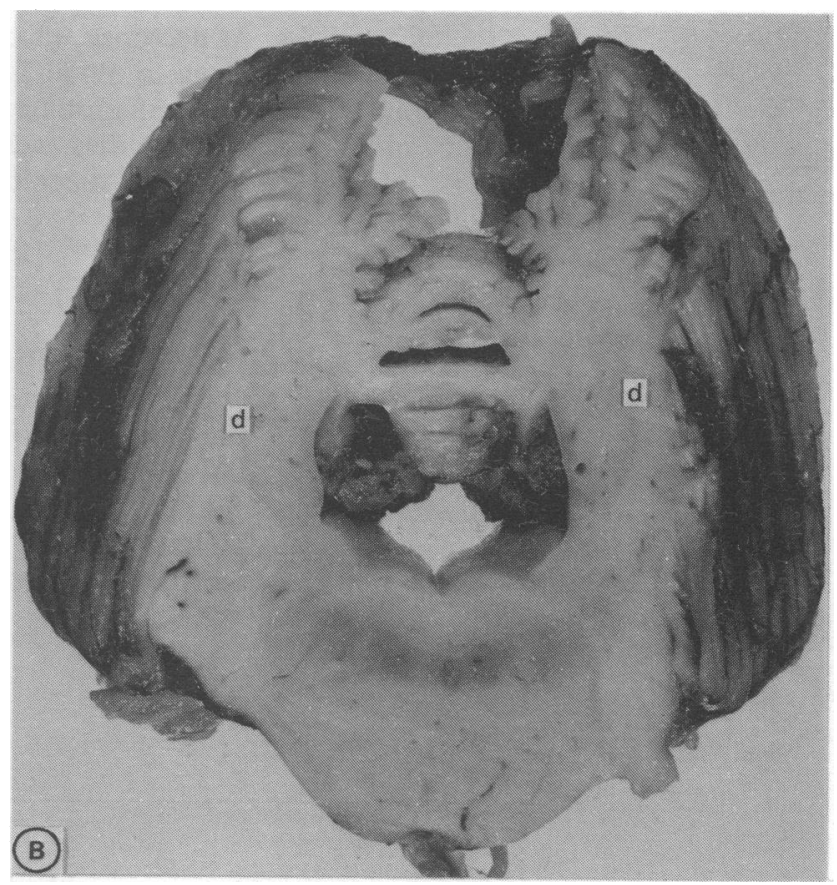

Figure 3 Case 1: $(A)$ base of the brain-the cerebellum is extremely small and the basal pons is shallow. (B) Horizontal section through the cerebellum and pons. Cerebellar folia and central white matter are white indicating gliosis, but the dentate ribbon (d) can still be discerned. Note the small basis pontis. 
no visual fixation. There was also limited abduction of both hips.

Ultrasound examinations showed a small cerebellum, a small quantity of ascites, and no abnormality of the heart. A barium swallow examination showed a sliding hiatus hernia with marked gastro-oesophageal reflux. The electroencephalogram showed no abnormality, but the electroretinogram and visual evoked response indicated some loss of function of the visual pathways and the brainstem auditory evoked response suggested disturbance of the brainstem pathways. Biochemical examination of serum showed a low albumin concentration and raised transaminase activities, although these abnormalities were less severe than those of his brother (table 1). There was no abnormality involving reducing substances, organic acids, or amino acids in the urine. Plasma amino acid concentrations were normal except those of proline and threonine, which were raised. The concentration of urate was also within the reference range. Thyroid studies showed that the concentration of thyroid stimulating hormone was high $(10.8 \mathrm{mU} / 1$; reference range $0.5-6$ $\mathrm{mU} / \mathrm{l}$ ), and total thyroxine concentration was low (38 nmol/1; reference range $90-195 \mathrm{nmol} / \mathrm{l}$ ) as was that of thyroxine binding globulin (3.6 $\mathrm{mg} / \mathrm{l}$; reference range $7-17 \mathrm{mg} / \mathrm{l})$. Serum lipid and lipoprotein concentrations were also measured (table 2). The lipoproteins were within the reference range with the exception of apolipoprotein $B$, the presence of which was indicated by immunoelectrophoresis, though it was not quantifiable.

After confirmation that he had the same condition as his brother his parents wanted him to return home, and he died of pneumonia at the age of 17 weeks. At necropsy, there was bilateral bronchopneumonia, a moderate pericardial effusion, and a small amount of ascites. The liver and brain abnormalities were similar to those of his brother, but the kidneys looked normal.

\section{SUBJECTS}

Serum samples from the two patients with olivopontocerebellar atrophy of neonatal onset were analysed together with samples from four groups of control subjects: 300 normal adults, 10 infants and children suspected of having olivopontocerebellar atrophy or DDD syndrome but in whom further investigation con-

Table 2 Serum lipid and lipoprotein concentrations in case No 2

\begin{tabular}{|c|c|c|}
\hline \multirow[t]{2}{*}{ Analyte (units) } & \multicolumn{2}{|c|}{ Serum concentration } \\
\hline & $\begin{array}{l}\text { Case } \\
\text { No } 2\end{array}$ & $\begin{array}{l}\text { Reference } \\
\text { range }\end{array}$ \\
\hline $\begin{array}{l}\text { Cholesterol (mmol/l) } \\
\text { Triglycerides (mmol/l) } \\
\text { High density lipoprotein cholesterol } \\
\text { (mmol/l) } \\
\text { Low density lipoprotein cholesterol } \\
\text { (mmol/l) by Friedewald equation } \\
\text { Apolipoprotein A I (g/l) } \\
\text { Apolipoprotein B (g/l) }\end{array}$ & $\begin{array}{r}3 \cdot 4 \\
1 \cdot 3 \\
1 \cdot 12 \\
0 \cdot 67 \\
1 \cdot 17 \\
<0 \cdot 30\end{array}$ & $\begin{array}{l}2 \cdot 3-4 \cdot 9^{19} \\
0 \cdot 6-1 \cdot 9^{19} \\
0 \cdot 6-2 \cdot 2^{19} \\
1 \cdot 7-3 \cdot 4^{1} \\
1 \cdot 15(0 \cdot 46)^{21 *} \\
0 \cdot 87(0 \cdot 58)^{21 *}\end{array}$ \\
\hline
\end{tabular}

${ }^{*}$ Mean (2 SD). firmed different diagnoses, two children with olivopontocerebellar atrophy of childhood onset with retinal degeneration (type III), ${ }^{5}$ and 17 infants aged 6 weeks to 12 months with cirrhosis but without the other features of the neonatal olivopontocerebellar atrophy syndrome (including infants with severely deranged liver function). Samples of serum were stored at $-20^{\circ} \mathrm{C}$ until analysis. Normal cerebrospinal fluid, which contains transferrin with $0-6$ sialic acid residues, was used as a reference sample to show the positions of all the transferrin bands (fig 4, lane A).

\section{METHODS}

The different forms of transferrin were separated by agarose isoelectric focusing. ${ }^{13}$ Briefly, an agarose gel $220 \times 110 \times 1 \mathrm{~mm}$ containing $4 \%$ carrier ampholytes (Pharmalyte 4-6.5) was loaded with approximately $40 \mathrm{ng}$ of transferrin $(2 \mu \mathrm{l}$ serum diluted 1:100). Focusing was carried out at $1000 \mathrm{~V}$ for 30 minutes. After transfer to cellulose nitrate the transferrin was detected immunochemically with sheep antihuman transferrin IgG peroxidase conjugate.

\section{Results}

Isoelectric focusing of serum transferrin from normal control subjects showed that transferrin containing four sialic acid residues (tetrasialotransferrin) was the main component (fig 4, lanes $B$ and $C$ ). In both of our patients with olivopontocerebellar atrophy of neonatal onset, transferrin isoelectric focusing showed pronounced increases in disialotransferrin and asialotransferrin, with a corresponding reduction in tetrasialotransferrin (fig 4, lanes D and E). In no other sample (including those from infants with cirrhosis caused by disorders other than olivopontocerebellar atrophy, and those from the two children with type III disease) was there a similar alteration of the transferrin isoelectric focusing pattern.

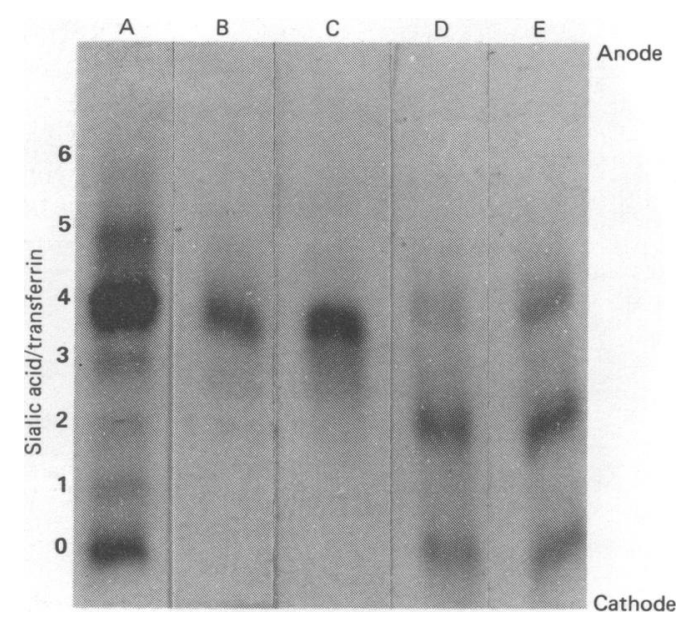

Figure 4 Isoelectric focusing of transferrin from samples of serum and cerebrospinal fluid. $(A)$ Represents normal cerebrospinal fluid, $(B)$ and $(C)$ serum from two normal subjects, and $(D)$ and $(E)$ serum from the two cases of olivopontocerebellar atrophy of neonatal onset. Numbers at the side incidate the bands corresponding to transferrin possessing 0 to 6 molecules of sialic acid. 
Discussion

The clinical and pathological findings in our two cases are essentially the same as those described in the four children previously reported with neonatal olivopontocerebellar atrophy. ${ }^{12}$ All six cases failed to thrive, and had developmental delay, hypotonia, abnormal eye movements, varying degrees of cirrhosis and fatty liver, and typical neuropathogical features. All six cases died before the age of 2 years. This contrasted with the cases of DDD syndrome which, at the time that they were reported, were all alive between the ages of 3 and 21 years. $^{6}$ Except for this one aspect, however, the similarities between the two conditions are striking. Features common to both disorders include failure to thrive, hypotonia, developmental delay, retinal abnormalities, joint restrictions, liver disease, pericardial effusion, diarrhoea, and cerebellar atrophy.

Kristiansson et al have shown that children with the DDD syndrome have a characteristic alteration in the pattern produced by isoelectric focusing of transferrin from serum and cerebrospinal fluid. ${ }^{6}$ Similar biochemical findings were also reported by Jaeken et al. ${ }^{7} 1014 \mathrm{We}$ have now shown that this pattern is also present in cases of olivopontocerebellar atrophy of neonatal onset. Whether this abnormality in the sialic acid content of serum serum transferrin is found in any other condition has been studied intensively. The results of transferrin isoelectric focusing on many thousands of serum samples have shown that similar patterns are seen only in cases of severe alcohol abuse, and these changes are usually less pronounced. ${ }^{6}{ }^{15}$ Our results show that infantile liver disease alone does not cause similar alterations in serum transferrin patterns.

Transferrin is not the only glycoprotein that is abnormal in olivopontocerebellar atrophy of neonatal onset and in the DDD syndrome. For example, low plasma concentrations of thyroid binding globulin and caeruloplasmin have been reported in both conditions. ${ }^{1289} \mathrm{~A}$ low serum concentration of the glycoprotein apolipoprotein B has been reported in olivopontocerebellar atrophy of neonatal onset (our case 2 and case 1 reported by Agamanolis et $a^{1}$ ). The results of lipid and lipoprotein analyses in our case 2 failed to show all the abnormalities reported by Agamanolis et al; the more generalised lipid abnormalities in the latter case may perhaps be explained by poor nutrition and more advanced liver disease. Interestingly, low concentrations of $\beta$-lipoproteins have been found during infancy in some patients with the DDD syndrome. ${ }^{6}$

The biochemical similarities combined with the remarkable clinical similarities between the DDD syndrome and olivopontocerebellar atrophy of neonatal onset suggest that they may represent parts of the range of a single genetic metabolic disease, or at least closely related inborn errors of glycoprotein metabolism. Any hypothesis about the precise site of the metabolic defect must explain how the sialic acid content of serum transferrin becomes deranged, how the serum concentrations of some (but not all) glycoproteins are substantially reduced, and how damage to the liver and parts of the central nervous system occurs. The sialic acid content of serum transferrin could be altered by an inborn error affecting the synthesis of the glycoprotein or by one affecting its degradation.

During synthesis of mammalian glycoproteins, the addition of sialic acid to galactose residues at the non-reducing terminals of antennas of complex asparagine-linked glycans occurs at a late stage in post-translational processing, and results in termination of the chain. It is catalysed by two $\beta$-galactoside $\alpha-2-3$ and $\alpha-2-6$ sialyl transferases, which show specificity towards both the glycosidic linkage of the receptor galactose residue and the branch on which it occurs. ${ }^{16}$ The number and the structure of the recipient oligosaccharide chains are themselves determined by the primary structure of the protein and by the activities of the processing glycosidases and glycosyl transferases in the cell in which it is synthesised. Thus a change in the number of sialic acid residues on the transferrin molecule could, in theory, be the result of a mutation in its structural gene or a change in the activity of any one of the processing enzymes up to and including the sialyl transferases that add the terminal sialic acid residues. A specific mutation in the transferrin gene, however, seems unlikely in view of the changes in other glycoproteins in these patients. The reported decrease in non-specific $\mathrm{N}$-acetylglucosaminyl transferase activity ${ }^{9}$ raises the possibility that one of the seven $\mathrm{N}$-acetylglucosaminyl transferases required to generate the range of branched structures in complex glycans may be defective. ${ }^{17}$

Serum sialidases (neuraminidases) can remove sialic acid residues from serum transferrin; the transferrin can then be removed from the circulation by the hepatic asialoglycoprotein receptor. ${ }^{18}$ Thus an alteration in the sialylation of serum transferrin could, in theory, result from increased serum sialidase activity or from a defective asialoglycoprotein receptor. The latter mechanism would, however, be expected to lead to an increase rather than a decrease in serum glycoprotein concentrations.

The correct explanation for the defect in the DDD syndrome and olivopontocerebellar atrophy of neonatal onset will probably have to await elucidation of the structure of the normal and abnormal transferrin glycans. The pathogenesis of organ damage is also unknown at present. The effects of a general disorder of glycoprotein metabolism are likely to be complex in view of the pleiotropic role of glycoproteins in cellular processes, cell-cell recognition, and transport.

We thank Dr R M Boustany for supplying serum from patient with olivopontocerebellar atrophy type III, and the technicians at the Medical Research Council Lipoprotein Unit, Hammersmith Hospital, London, for measuring serum lipid and lipoprotein concentrations.

1 Agamanolis DP, Potter JL, Naito HK, Robinson HB, Kulasekran T. Lipoprotein disorder, cirrhosis, and olivopontocerebellar degeneration in two siblings. Neurology 1986;36:674-81.

2 Harding BN, Dunger DB, Grant DB, Erdohazi M. Familia 
olivopontocerebellar atrophy with neonatal onset: a recessively inherited syndrome with systemic and biochemical abnormalities. I Neurol Neurosurg Psychiatry 1988;51:385-90.

3 Menzel P. Beitrag zur Kenntnis der hereditaren Ataxien und Kleinhirnatrophie. Archiv für Psychiatrie and Nervenkrankenheiten 1891;22:160-90.

4 Dejerine J, Thomas A. L'atrophie olivo-ponto-cerebelleuse. Nouvelle Iconographie de la Salpêtrière, Clinique des Maladies due Système Nerveux 1900;13:330-70.

5 Konigsmark BW, Weiner LP. The olivopontocerebellar atropies: a review. Medicine 1970;49:227-41.

6 Kristiansson $B$, Andersson $M$, Tonnby B, Hagberg $B$. Disialotransferrin developmental deficiency syndrome. Arch Dis Child 1989;64:71-6.

7 Ramaekers V, Stibler H, Kint J, Jaeken J. A new variant of the carbohydrate deficient glycoproteins syndrome. Proceedings of the 28th Annual Symposium of the Society for the ceedings of the 28th Annual Symposium of the Society for the
Study of Inborn Errors of Metabolism. Birmingham: SSIEM Study
1990.

8 Jaeken J, Vanderschueren-Lodeweyckx M, Caesar P, et al. Familial psychomotor retardation with markedly fluctuating serum prolactin, FSH and GH levels, partial TBG deficiency, increased serum arylsulphatase $A$ and increased CSF protein: a new syndrome? Pediatr Res 1980;14:179.

9 Jaeken J, Eggermont E, Stibler H. An apparent homozygous $\mathrm{X}$-linked disorder with carbohydrate-deficient serum glycoproteins. Lancet 1987;i:1398.

10 Stibler $\mathrm{H}$, Jaeken J. Carbohydrate deficient serum transferrin in a new systemic hereditary syndrome. Arch Dis Child 1990;65:107-11.

11 de Jong G, van Eijk HG. Microheterogeneity of human transferrin: a biological phenomenon studied by isoelectric focusing in immobilized pH gradients. Electrophoresis 1988; 9:589-98.
12 Jaeken J. Disialotransferrin developmental deficiency syndrome and olivopontocerebellar atrophy. Arch Dis Child 1989;64:764-5.

13 Keir G, Luxton RW, Thompson EJ. Isoelectric focusing of cerebrospinal fluid immunoglobulin G: an annotated update. Ann Clin Biochem 1990;27:436-43.

14 Jaeken J, van Eijk HG, van der Heul C, Corbeel L, Eeckels R, Eggermont E. Sialic acid-deficient serum and cerebrospinal fluid transferrin in a newly recognized genetic syndrome. Clin Chim Acta 1984;144:245-7.

15 Stibler $\mathrm{H}$, Borg S, Allgulander C. Clinical significance of abnormal heterogeneity of transferrin in relation to alcohol consumption. Acta Med Scand 1979;206:275-81.

16 Beyer TA, Sadiler JE, Rearick JI, Paulson JC, Hill RL. Glycosyltransferases and their use in assessing oligosaccharide structure and structure-function relationships. Adv ride structure and structure

17 Schachter $\mathrm{H}$. Coordination between enzyme specificity and intracellular compartmentation in the control of proteinbound oligosaccharide biosynthesis. Biol Cell 1984;51 $133-45$.

18 Ashwell G, Harford J. Carbohydrate specific receptors of the liver. Annu Rev Biochem 1982;51:531-54.

9 Lloyd JK. Plasma lipid disorders. In: Clayton BE, Round JM, eds. Chemical pathology and the sick child. Oxford: Blackwell, 1984:245-64.

20 Warnick GR, Knopp RH, Fitzpatrick V, Branson L. Estimating low-density lipoprotein cholesterol by the Friedewald equation is adequate for classifying patients on the basis of nationally recommended cutpoints. Clin Chem 1990;36:15-9.

21 Alaupovic P, McConathy WJ, Fesmire J, Tavella M, Bard JM. Profiles of apolipoproteins and apolipoprotein Bcontaining lipoprotein particles in dyslipoproteinemias. Clin Chem 1988;34:B13-27.

\section{A spoonful of sugar}

Mary Poppins' advice may well upset dentists but there appears to be more to the calming effects of sugar than meets the eye. Workers in Baltimore (Elliott Bass and Lisa Hoffmeyer, Pediatrics 1991; 87: 215-8) have shown that giving a small amount of sucrose by mouth to newborn babies before heel prick blood letting reduced the amount and duration of subsequent crying compared with that in babies given only water. Crying in babies after circumcision was also reduced by sucrose. Babies given nothing cried for $67 \%$ of the time after the procedure, those given a dummy moistened with water cried for $49 \%$ of the time, and those given a dummy soaked in $24 \%$ sucrose solution cried for $31 \%$ of the time. The effect is thought to outlast the taste of sugar. Previous studies on rats have given similar results and the effect was eliminated by pretreating the animals with an opiate antagonist suggesting that it might be mediated by endogenous opioids.

These studies are of great theoretical interest and sucrose as a calmer for minor procedures seems acceptable but for more painful procedures, including circumcision, it is difficult to justify withholding more effective pain relief. There is no doubt that newborn infants respond to pain and surgical stress ${ }^{1}$ and they deserve to be treated properly in this respect.

\section{ARCHIVIST}

